\title{
Aldehyde Dehydrogenase, Mitochondrial
}

National Cancer Institute

\section{Source}

National Cancer Institute. Aldehyde Dehydrogenase, Mitochondrial. NCI Thesaurus. Code C84997.

Aldehyde dehydrogenase mitochondrial protein (517 aa, 56 kDa) is encoded by the human ALDH2 gene. This protein is involved in intermediary metabolism. 